\title{
Gözyaşı Vadisi'nde Kaybetmeye Yazgılılar: Mihail Lermontov ve Demon
}

\author{
Dr. Öğr. Üyesi Nazan Coşkun \\ Artvin Çoruh Üniversitesi, Fen Edebiyat Fakültesi \\ Rus Dili ve Edebiyatı Anabilim Dalı \\ nazan_coskun@artvin.edu.tr
}

Öz

Demon, Rus edebiyatının isyankar dehası olarak kabul edilen Mihail Yuryeviç Lermontov'un (1814-1841) yirmi yedi yıllık kısa yaşamının on yılı boyunca üzerinde çalıştığ eseridir. Eserin ana teması ilk bakışta İncil'de geçen düşmüş melek, cennetten kovulan şeytanın dünyevi aşkla yeniden doğmaya dayanan ancak yenilgiyle sonlanan yaşamından bir kesite dayanıyor gibi görünür. Zira insan ve şeytanın yolu ilk günahla kesişir ve şeytan, Âdem ile Havva'nın bilgi ağacı meyvesini yemesini sağlayarak insanoğlunun dünyevi yaşamını başlatır. İnsan, cennetten kovularak dünya denen "gözyaşı vadisine" gönderilir. Tanrısal yaratımın tacı olan insan ile isyandan önce baş melek olan bu iki varlığın beraber girdikleri düşüş yolu, eserde kurtuluş yolu ile bir kez daha kesişir. Ancak detaylı bir inceleme, eserin bu dar çerçeveye yerleştirilmesinin düşünsel, toplumsal-politik içeriğini kısırlaştırdığını gözler önüne serer. İncil teması burada felsefi açıdan anlamlı bir çatışmayı kapsayan dışsal bir çerçeve olarak yer alır. Zira eser; yazar ve kahraman özdeşliğinde Lermontov'un içinde yaşadığ çağ ve evrene yönelik bireysel dünya duyumsayışına dair derin izler barındırır. 1830'lu yıllar Rusya'sında birey ve toplumsal yapı arasındaki çelişkiler keskinleşir. Bireyin kendini gerçekleştirme imkânının olmadığı toplumsal gerçeklik, Lermontov ve kahramanı Demon için sürgün bir ruh olarak dolaştıkları gözyaşı vadisini sembolize eder. Çalışmamız kapsamında bu sonuca Lermontov'un Demon adlı eseri bağlamında dünya denen gözyaşı vadisinde şeytanın yazgısı, yazar-kahraman ve gözyaşı vadisinin Lermontov için mekânı olan Çar I. Nikolay Rusya'sı ekseninde incelenmesi yapılarak ulaşılmıştır. Kahraman ile yazar arasında özdeşlik kurma noktasından hareket edilmiş, değerlendirmeler dini ve toplumsal çerçeveden iki farklı yaklaşımla gerçekleştirilmiştir.

Anahtar Kelimeler: Lermontov, Rus Edebiyatı, Demon, Rusya, Çar I. Nikolay.

\section{Those Who Are Destined to Lose in The Valley of Tears: Mikha1l Lermontov and The Demon}

\begin{abstract}
Demon, the poem of Mikhail Yuryevich Lermontov (1814-1841), often who is regarded as rebellious genius of Russian literature, took ten years of the writer's short twenty-sevenyear life to complete. The main theme of the work, at first glance, seems to be based on a fragment of the life of the fallen angel, who was expelled from heaven, based on rebirth with earthly love but that ends in defeat. When the man and the devil's paths crossover in the
\end{abstract}


original sin, the devil initiates the earthly life of man by making Adam and Eve eat the fruit of the tree of knowledge. Man is expelled from heaven and sent to the "valley of tears" called earth. The paths of the downfall of these two beings, of man, who is the crown of divine creation, and the one who was an archangel before the rebellion, coincides once again with the path of salvation in the work. However, a detailed examination reveals that placing the work in this narrow frame weakens its intellectual, socio-political content. The biblical theme functions here as an external framework which encompasses a philosophically meaningful conflict. Moreover, the work, due to the close identity between the author and protagonist, contains deep traces of Lermontov's individual sense of the world towards the period and the universe that he lived in. In Russia of the 1830s, the contradictions between the individual and the social structure deteriorated. The social reality, in which the individual has no opportunity to realize himself, symbolizes the valley of tears where Lermontov and his protagonist demon wander as exiled spirits. Within the scope of our study of Lermontov's Demon, the conclusion was reached by examining the fate of the devilin the valley of tears called the world, the writer-hero and Russia of Tsar Nicholas I as the valley of tearsforLermontov. Having started from establishing an identity between the protagonist and the author, the two different approaches within a religious and social framework are used to carry out the evaluations.

Keywords: Lermontov, Russian Literature, Demon, Russia, Tsar Nikolas I. 


\title{
GİRIŞ
}

\author{
Gökle barışmak istiyorum, \\ Sevmek istiyorum, yakarmak, \\ Inanmak iyiliğe
}

(Lermontov, 2019, s. 98).

İlahi dinlerde şeytan; düşmüş melek imgesinde kötülük, baştan çıkarma gibi olgularla ilişkili olarak karşımıza çıkar. Antik mitolojide insan ruhuna özgü oldukça farklı özellikleri simgeleyen şeytan, çileci Hristiyan ahlakı çerçevesinde bütünsel olarak olumsuz bir imgeye dönüşür. Cennet ve yeryüzü arasında dolaşan ve insanın Tanrı'larla iletişim kurmasına yardım eden gizemli ruhlar, kötülüğün ruhlarına evrilirler (Loginovskaya, 1977, s. 14). Tanrısal yaratımın tacı olarak kabul edilen insan ile düşüşten önce baş melek olan şeytanın yollarının kesişmesi, şeytanın Tanrı'ya başkaldırmaya dayanan ilk günahından sonra insanoğlunu da ilk günaha sürüklemesi ile başlar. İnsanoğlunun ilk günah hikâyesinde baştan çıkarıcı yılan olarak karşımıza çıkan şeytan, Âdem ile Havva'yı bilgi ağacı meyvesini yemesi için ikna ederek cennetten kovulup yeryüzüne gönderilmelerine neden olur. Bilgi ile günahın özdeşleştirildiği ilk günah öğretisine göre yeryüzündeki kötülüğün temel nedeni de insanoğlunun itaatsizliği ile başlayan bilgi ile özdeş tutulan Tanrı'dan yabancılaşma sürecidir. Âdem ile Havva'yı bilgi ve özgürlük vaadi ile kandıran şeytan, insanoğlunun dünyevi tarihini başlatmış olur. Zeynep S. Balıkçığlu'nun sözleriyle; "tarih insanın cennetten kovulduğu an başlar. İnsan cennetten kovulmasıyla kendi yaratısı olmayan bir sonsuzluktan, kendi yaratısı olan bir sorumluluğa geçer" (Balıkçıŏlu, 1994, s. 22).

Şeytan ve insan arasındaki kadim ilişki, Hristiyanlığın oldukça güçlü bir gelişim süreci geçirdiği Ortaçağ'da belirgin bir görünüm kazanır. "Erken ortaçağdan itibaren ilk günah ile ilişkili olarak insanlığın şeytanın gücü altında olduğu konusunda ortak bir düşünce hâkim olur" (Russell, 2018, s. 144). Ancak Hıristiyanlığın kurtarıcı figürü İsa, çarmıhta yitirdiği dünyevi bedeni ile insanoğlunun ilk günahının kefaretini öder ve insanlığı şeytanın hâkimiyetinden kurtarır. Bu durumda doğrudan şu soru ortaya çıkar: İsa'nın ölümünden sonraki dünyada kötülük, şeytan yok olmuş mudur? Hayır! Peki, o zaman ilahi dinlerin iyi Tanrı ile dünyevi kötülük sorunu üzerine söylemlerindeki çelişkiyi aşmak nasıl mümkün olacaktır. Teodise kapsamında yer alan bu sorun, Hıristiyan teolojisi bağlamında iyi Tanrı ve özgür iradeyi kötüye kullanan insan açıklamasıyla çözümlenir. Özgür iradeyi kötüye kullanan insan, bedene hapsolarak yeryüzünde yaşamaya mahkûm edilir. Nitekim Norman Hampson, insanın ilk günahtan sonraki yeryüzü yaşamını "dünya denen gözyaşı vadisinin yanlışlarla dolu yollarında yürümek" (Hampson, 1991, s. 62) olarak tanımlar. Lermontov'un Demon adlı eseri bağlamında dünya denen gözyaşı vadisinde şeytanın yazgısı yazar-kahraman ve gözyaşı vadisinin Lermontov için mekânı olan Çar I. Nikolay Rusya'sı olarak karşımıza çıkar.

\section{Lermontov ve Demon: Kaybedenlerin Hikâyesi}

Yirmi yedi yıllık kısa yaşamında pek çok şiir, roman ve poema kaleme alan Lermontov, Demon adlı eseri üzerinde neredeyse bütün bir hayatı boyunca çalışır. Yazar, 1829 yılında henüz on beş yaşında bir delikanlı iken kaleme almaya başladığı, sekiz farklı versiyona sahip olan eserini 1839 yılında tamamlar. Lermontov'un çağdaşlarından Nikolay Gogol, şairin Demon üzerinde bu kadar uzun süre çalışmasını "baştan çıkarıcı bir şeytanın üzerindeki gücünü fark eden şair adeta ondan bir ayetle kurtulmak istercesine bu imgeyi pek çok kez yeniden betimler" (Gogol, 1952, s. 402) sözleriyle açılar. Lermontov'un tüm 
yaratıcılığı boyunca sürecek olan şeytan ile yolculuğu, 1829 yılında kaleme aldığı Benim İblisim (Мой демон) adlı şiiri ile başlar.

Kötülük meclisidir onun dünyası.

Dumanlı bulutların arasında uçarken

Irmakların köpürdeyişi, meşelerin hışırtısı

Ve yomsuz firtınalardır hoşuna giden.

$\cdots$

Tüm yakarışları çevirirken geri

Seyreder akan kanı umursamazca

Çă̆ıldamasın yüce hislerimin

Boğar tutkularının sesiyle

Ürkütür uysal esin perimi benim

Dünyasal olmayan gözleriyle(Lermontov, 2014, s. 148).

Yukarıdaki dizelerde görüldüğü üzere bu şiirde şeytan imgesi, döktüğü kanı umursamazca seyreden bir kötülük ruhu olarak betimlenir ve şairin şeytana olan yaklaşımı başka bir dünyaya ait gözlerle esin perisini ürküten bir varlık olarak olumsuzluk arz eder. Lermontov'un şeytanla uzun yolculuğunun anlatımı olarak ele alınabilecek Demon, yazarın en gizemli ve karmaşık eseri olarak kabul edilir, bu doğrultuda eserin düşünsel içeriğine, ana temasına yönelik söylemler de çeşitlilik arz eder. Eserin düşünsel içeriğine yönelik temel yarg1; John Milton'un Kayıp Cennet, Johann Goethe'nin Faust, George Byron'un Kabil, Alfred de Vigny'nin Eloa adlı eserleri gibi geniş bir yelpazeyi kapsayan İncil'de geçen düşmüş melek olarak şeytan imgesinin Lermontov ruhunda yeniden işlenişi, başka bir ifade ile bilinen bir temanın yeniden ele alınışdır (Bkz. Udodov, 1973). Bu yaygın kanı, eserin içeriği göz önünde tutulduğunda doğrudur. Ne var ki eseri bu dar çerçeveye sıkıştırmak yanlış bir yaklaşım olacaktır. Nitekim eserde İncil'de geçen hikâyeye yönelik doğrudan bir söylem bulunmamaktadır, ana tema bu konuyu çağrıştırsa da düşüşün nedeni sisler içindedir, şeytan daha çok cennetten yeryüzüne düşmüş sefil yazgısı olan bir melek olarak betimlenir ve insani özellikleri oldukça baskındır (Andreyevski, 1913, s. 173-200). Eser “Kederli İblis, sürgün ruh/ Günahkâr dünyanın üzerinde uçuyordu" (Lermontov, 2019, s. 67) dizeleri ile başlar. Burada kederli sıfatının altının çizilmesi gerekir. Zira hangi şeytan bu sıfatla anılabilir ki. Nitekim araştırmacı A. Jestkova, kederli Demon imgesi, beyhude bir biçimde barış, kendisiyle ve dünyayla uzlaşma arayan insan ruhu kavramına daha yakındır der ve bu nedenle, Lermontov kahramanına "sürgün ruh" dediğinde, İncil'de geçen şeytan ya da şeytana yakın olan diğer karakterlerini temel almak gerekmediğini belirtir (2014, s. 6671). İncil'de yer alan konu burada yalnızca geniş, felsefi açıdan anlamlı bir çarpışmayı içeren dış kabuk olarak mevcuttur (Loginovskaya, 1977, s. 22). Bu doğrultuda şairin yaratıcılığı ve yaşam mücadelesi bir bütün olarak değerlendirildiğinde eserin analizini İncil teması bağlamından ziyade şeytanın yazgısını, yazar-kahraman ve söz konusu dönemin Rus gerçekliği çerçevesine yerleştirmek önem arz etmektedir. Bu doğrultuda Lermontov'un içinde yaşadığı çă̆ değerlendirilirken kahraman ile yazar arasında özdeşlik kurma noktasından hareket edilecektir.

1814 yılında Moskova'da dünyaya gelen Lermontov'un dünya duyumsayışı, 1825 yılında tahta geçen Çar I. Nikolay Rusya'sının toplumsal ekonomik koşulları çerçevesinde oluşur. Çar I. Nikolay, Dekabrist ayaklanması ile başa geçtiği üzere oldukça sert bir yönetim politikası izler. İdamlar, sürgünler, her türlü düşünsel hareketin önünde engeller yaratma, ağır sansür yasaları Nikolay Rusya'sının başlıca özellikleri arasında yer alır. Lermontov, 
gençlik yıllarından itibaren Nikolay Rusya'sının toplumsal politik düzenine karşı ateşli bir protesto ve isyana girişir. Bu isyanın en güçlü örneği şairin hem bir şair olarak doğuşunu başlatan hem de ölüm yolunu açan ünlü Şairin Ölümü (Смерь поэта) adlı şiiridir. Aleksandr Puşkin'in 1837 yılında düelloda öldürülmesi ile bu olayın arkasındaki politik entrikayı bilerek öfkeyle zehir zemberek dizeler kaleme alan şair, sürgünle alır cevabını. Bu bağlamda Lermontov'un içinde yaşadığı düzenle savaşmak için isyankâr mücadele yolları arayışları, acı veren hayal kırıklıkları ile ilişkilidir. Şair, pratik bir sonuç bulamayan yılmaz protestosunu, görkemli isyancının görkemli imgesine - Demon'a yönlendirir (Nikoleva, 1956, s. 152). Demon, Tanrı'nın ve onun kusurlu yaratımının, yeryüzündeki yaşamın düşmanıdır tıpkı Lermontov gibi. Lermontov'u Demon ile özdeşleştirmeye dayanan yaklaşımımızın ilk izleri eser üzerine çalışmaya başladığı 1829 yılında kaleme aldığı Dua (Молитва) adlı bir diğer şiirinde de yansıma bulur:

Tanrım suçlama beni yalvarırım

Yalvarırım linçleme

...

Bana dar geliyor diye dünya

Ve sana sokulamadı̆̆ım için korkumdan

Ve sık sık günahkâr şarkılarımla

Yakardığım sen olmadığından(Lermontov, 2019, s. 2).

Yukarıdaki dizelerde görüldüğü üzere Lermontov, ne Tanrı'nın insanoğlunu gönderdiği yeryüzü ve gözyaşı vadisi ile uyuşmakta ne de bu yaratımın sahibine yaklaşmaktadır. Derin bir yalnızlığa mahkûmdur. Lermontov'un zihni, gençliğinden itibaren insanların olağan yolundan sapar. Dünyaya onların gözleriyle değil, farklı gözlerle bakar. Hırsları onun tutkuları ile uyuşmaz, hedefleri ona yabancıdır, sevinçleri ve kederleri farklıdır (Viskovatıy, 2004, s. 142). Araştırmacı Sakulin, şeytani ilkenin tüm güçlü insanlarda var olduğu düşüncesinden hareket ederek Demon'un hikâyesinin büyük ölçüde Lermontov'un kendi itirafı olduğunu söylemenin abartılı olmayacağını ileri sürer (1914, s. 155). Eserde Demon'un hikâyesi cennet yaşamına dair anımsayışlarla başlar. Günahkâr dünyanın üzerinde uçarken temiz bir ruh, baş melek olduğu günleri anımsar. Bu anımsayış içinde "Bilmek tutkusuyla her şeyi/ Sonsuz dumanlar arasından/ İzlerdi fırlatılmış gezegenlerin/Enginliğinde göz eden kervanları" (Lermontov, 2019, s. 67) dizeleri oldukça önemlidir. Bu dizelerde Demon'un bilmek tutkusunun altını çizmek gerekmektedir. Zira insanın ilk günahının kökenini oluşturan bilgi ağacı meyvesine gönderme olarak kabul edilebilir. Demon'u şimdi içinde yaşadığı dünyaya sürükleyen bilgi, dünyevi trajedisinin de başlangıcını oluşturur. Demon'un cennet yaşamını betimleyen öğeler; inanç ve sevgidir, kötülüğü, kuşkuyu bilmeden huzur içinde bir yaşam sürdürmektedir. Eser Demon'un yeryüzündeki yolculuğunun kederli betimi ile devam eder:

Çoktandır lanetli, başıboş geziyordu

Sığınaksız dünya çölünde:

Çă̆lar birbiri ardına geçiyordu,

Dakikalar tek düze bir strayla

Birbirini nasil izlerse(Lermontov, 2019, s. 68).

Demon, bir taraftan dünyevi yaşamı "Korkak ve soğuk insanların /Dar çevresinde susarak solmak" olarak tanımlar diğer taraftan güçlü bir arzuyla bu hayata katılmak ister. Ne var ki bunu gerçekleştirmenin nesnel olarak imkânsızlığının da bilincindedir. Bu bilincin yarattığ1 çelişki, trajik, gururlu bir umutsuzluğa dönüşür. Böylece sağlam ve kibirli 
konumunda bir çatlak oluşur. Varoluşunun içsel tutarsızlığının, çelişkisinin bilincine varır, onu yaşamdan ayıran bireysel isyanın anlamsızlığını ve yararsızlığını kabul eder. Hem dünya hem de cennet kendi yasalarına göre işlemekte, Demon'a ihtiyaç duymamaktadır oysa Demon'un onlara ihtiyacı vardır. Bu duygular içinde Demon kederle cennetteki günlerini anımsar ve soğuk bir kıskançlıkla dünyaya bakar. İçsel çelişkiler Demon'un düşüncelerini harekete geçirir, yeniden hem dünyayla hem de cennetle bağ kurmak ister. Ancak ne ruhundaki kötülük tohumunu ve her iki dünyaya olan kibirli nefretini aşma ne de mücadeleden vazgeçme gücüne sahiptir. Böylece Demon'un karşısına birbiri ardına üç manzara çıkar: önce görkemli Kafkas dağ manzarası, sonra Gürcistan'nın renkli vadileri ve son olarak Demon'un Tamara'nın dansını gördüğü Gudal sarayı. Demon'un hikâyesinin mekânının Kafkasya olması şair ve kahraman özdeşliğinde ayrıca önem taşımaktadır. Lermontov, Kafkasya doğası ile küçük bir çocukken büyükannesinin onu tedavi amacıyla buraya getirmesi ile ilk kez tanışır ve Kafkasya şairin yaşamının vazgeçilmez mekânlarından biri, özellikle de sürgün mekânı olur. Lermontov uzmanı Viskovatıy'ın sözleriyle "Kafkasya uzak, vazgeçilmez bir vatan imgesine" (Viskovatıy, 2014, s. 29) dönüşür Lermontov için. Bu anlamda Lermontov'un vazgeçemediği, huzur bulduğu Kafkasya, kahramanının da yeniden doğuş umudunun mekânı haline gelir.

Demon'un Tamara'yı gördüğü ilk an, Gudal sarayında düğün hazırlıklarının yapıldığı zamana rastlar. İki dünyaya da kendisini bir yabancı olarak duyumsayan Demon, evlenmek üzere olan Tamara'yı gördüğü an ona âşık olur ve yeniden doğuş ışığını bir Kafkas güzeli olan Tamara'da bulmaya çalışır. Uzaktan bakıldığında, bu ahenkli yaşam, akıldan arındırılmış cennet mutluluğunun görüntülerine benzer. Demon'u Tamara'da cezbeden şey her şeyden önce canlı, bütünsel yaşam imgesidir yani Demon'un kaybettiği şeydir. Lermontov'un kendisini yabancı duyumsadığı Nikolay gerçekliğindeki kurtuluş, yeniden doğuş ışığına baktığımızda ise tıpkı Demon'da olduğu gibi güçlü bir yâdsıma ve mücadele arzusu karşımıza çıkar. Araştırmacı Ulrich Foht, Demon ile Lermontov'u özdeşleştirmeye dayanan incelememizi Demon ile 1830'lu yıllar Rus aristokrasisini özdeşleştirmeye dayanan bir genellemeye vardırır. Foht'a göre Çar I. Nikolay Rusya'sının toplumsal ekonomik koşullarında Rus aristokrasisi eski baskın konumundan yoksun bırakılır, toplumsal olarak izole edilir, kültürel ve maddi gücünü belirli ölçüde korusa da yeni konumundan memnun değildir, kendi içine kapanmıs, kibirli bir umutsuzluğa kapılmış durumdadır. Foht, bu süreci kapitalist gelişme ile ilişkilendirerek aristokratik monarşinin yerini burjuvazinin ihtiyaçlarını dikkatle dinleyen bürokratik bir monarşiye bırakması ile açıklar. Ancak Rus soyluların hala kültürel ve ekonomik olarak büyük bir güce sahip olması, tarihsel sahneden inişlerinin de yavaş yavaş gerçekleşmesini sağlar. Kendilerini "dışlanmış" olarak duyumsayan bu tabaka, koşullara adapte olma, mistisizme sığınma gibi çeşitli kaçış veya kurtuluş yollarına başvurur. Foht'a göre "dışlanmışların" mücadele yollarından biri de Demon ile sembolize edilen Rusya'nın yazgısına dair tartışmaların teorisyenleri, ideologları rolüne bürünmektir. 1830'lu yılların önde gelen düşünürlerinden biri olan P.Çaadayev'i bu kategoride değerlendiren araştırmacı, Demon ile düşünür arasındaki özdeşlikte geçmişe duyulan özlemin altını çizer: Demon'un tüm çabasına tek bir özlem nüfuz eder - geçmişin geri dönüşüyle içsel bütünselliğe erişmek (Foht, 2013, , s. 755-781.s. 107-146). Tamara'ya onu sevmesi için yalvarır zira karşılıklı aşk içinde sadece geçmişe dönmenin sevincini bulmak ister:

Beni iyiliğe ve göklere

Döndürebilirsin tek bir sözcükle; 


\section{Senin aşkının kutsal örtüsüne}

Bürünüp çıarım Tanrı huzuruna;

Yeni bir melek gibi, yeni bir ışıkta(Lermontov, 2019, s. 91).

Foht'un bu düşünceleri, Lermontov'un da üyesi olduğu 1830'lu yıllardaki Rus soylu aydınları için kısmen doğrudur. Geçmişe dönüş, tüm soylu aydınların paylaştığı düşünce olmasa da Çaadayev örneği konumuz bağlamında önemlidir. Çaadayev de tıpkı Demon ve Lermontov gibi mahkûm olduğu gerçekliğe karşı çıar, onunla teorisyenlik bağlamında mücadeleye girişir ancak Çaadayev'in geri dönüş vurgusu, Foht'un sözünü ettiği ülkenin siyasi yaşamında yer alma isteği gibi toplumsal-politik bir alana sığdırılamaz sadece. Düşünür, Rusya tarihini "başlangıçta vahşi bir barbarlık, sonra kaba bir batıl inanç, daha sonra sonuç olarak ulusal egemenliğin miras aldığı katı ve alçaltıcı bir yabancı hâkimiyeti" (Çaadayev, 2009, s. 92) sözleriyle karakterize eder ve felsefesinin merkezine Tanrı ile bütünleşmeyi koyar. Nitekim bu çerçeve, Foht'un Demon ile Çaadayev'in mücadelesini özdeşleştirme düşüncelerine çok daha derin bir temel sağlar. Zira Demon'un özlem duyduğu geçmiş ile Çaadayev'in arzuladığı geçmiş, aynı kaynaktan beslenir: ilk günahtan önce Tanrı ile bütünselliğin olduğu yaşam. Bir diğer araştırmacı Loginovskaya da Foht ile benzer düşüncelerden yol çıkarak Lermontov'un eseri ile 1830'larda ve 1840'ların başlarındaki Rus düşüncesi arasındaki bağa vurgu yapar. Araştırmacıya göre burada daha yüce, sembolik bir düzlemde Demon'un deneyimlerine de yansıyan bir zihin durumunun açığa çıktığını anlamak için özel bir kavrayışa ihtiyaç yoktur, geçiş dönemi insanlarının karakteristik ruh halidir vurgulanan. Bu ruh hali en geniş anlamıyla Büyük Fransız Devrimi ve Napolyon savaşlarını takip eden süreçte- başlangıçta güçlü bir umut ve hayallerin yükselişinden sonra - insanlığın özgürlük ve mutluluk hayalini gerçekleştirme yetisine duyulan inancın sarsılması ile karakterize olan dönemi ifade eder.

Dar manada Rusya açısından değerlendirildiğinde bu çağ, ortak Avrupa tarihsel sürecinin özünü derinden anlayan ilerici, düşünen aydınların Avrupa ile aynı hayal kırıklığını yaşamasının yanı sıra, aynı zamanda Rus toplumsal tarihinin Dekabrist ayaklanması gibi belirli olayların neden olduğu yeni hayal kırıklıklarını da kapsayan bir dönemi ifade eder. Zira Dekabrist ayaklanmasından sonraki toplumsal-politik koşullar, Rusya tarihinin en zorlu koşullarının oluştuğu dönemi kapsar. Napolyon savaşları ile Avrupa'nın çehresini aşan ortak insanlık onuru fikirleri, Fransız devrimi fikirleri, Rusya'da güçlü bir yankı bulur ve Dekabrist hareketi yaratır. Dekabristler her ne kadar anavatana doğrudan bir fayda sağlayamadan idamlarla, sürgünlerle heba edilmiş olsalar da Rusya'nın zihinsel gelişiminde yeni bir çağı açarlar. Demon'da ifade edilen bu hayal kırıklığı ile biçimlenen atmosfer ve dünya duyumsanışıdır (1977, s. 65-66). Demon'un yazarı Lermontov da bu atmosferde nefes almaya çalışan ve içinde yaşadığ ${ }_{1}$ çağ ve insanlara derinden bağll, bir birey ve yazardır. Nitekim söz konusu dönemin önde gelen düşünürlerinden Aleksandr Hertsen, Lermontov'a dair şöyle yazar:

Lermontov, onu içinde yaşadı̆̆ çağa bağlayan yüreğindeki tüm tellerin sonsuz bir güçle çılayan, yaratıcı dehası bireysel izlenimleri, deneyimleri ve düşüncelerinden bütünsel olarak kopamayan doğalardandır. Bu tür doğalar genellikle yerleşik toplumsal yaşam formlarmnn dağıldı̆̆gl, toplumda şüphecilik ve ahlaki çözülmenin hüküm sürdüğü geçiş dönemlerinde ortaya çıar. Görünüşe göre insanlğ̆m en saf idealleri bu doğalarda kendine bir sığınak bulur, onların ağzzından ilan edilir. Toplumun ahlaksızlklarını damgalayarak

SEFAD, 2021; (46): 103-118 
kendi yaralarını, hataların ve iç mücadelelerini ortaya çıkarırlar aynı zamanda bu çürümüş dünyayı kurtarıp iyileştirirler...(Hertsen, 1989, s. 136-137).

$\mathrm{Bu}$ çerçevede bir bütün olarak bakıldığında Demon, iki dünyaya da ait olamayan isyankâr bir ruh olarak genel bağlamda dönemin Rus aydınlarını özelde Lermontov'un kendisini yansıtır. Ancak bu özdeşlikte Demon'un isyanı, Lermontov'un çağdaşlarına yönelik eleştirileri dikkate alındığında Lermontov'a çok daha yakındır. Lermontov, 1838 yılında kaleme aldığı "Kaygiyla bakıyorum bizim kuşağa!" dizeleriyle başlayan ünlü Düşünce (Дума) şiirinde çağdaşlarını iktidar karşısında umarsızlığa kapılmış tutsaklar olarak tanımlar:

Utanç verici bir umursamazlı̆̆ımız var iyiye ve kötüye,

Solup gidiyoruz kavgaya girmeden daha;

Yüz kızartıcı korkaklarız tehlikeyi görünce

Ve iğrenç tutsaklarız iktidar karşısında (Lermontov, 2019, s. 25).

Lermontov'un çağdaşlarına yönelik serzenişleri Demon'un Tamara'ya açıkladığ dünyevi yaşam ve insanlara yönelik düşüncelerinde de duyumsanır:

Nedir ki onlar? Ne anlamı var

Yaşamlarının ve çabalarının?

Geçip gittiler ve geçip gidecekler!(Lermontov, 2019, s. 95 ).

Lermontov ve Demon'un sözlerinde açıkça hissedilen eylem ve mücadele arzusudur. Ne var ki Demon'un kurtuluş mücadelesi çelişkilerle ilerleyecektir. Tamara'nın aşkının kutsal örtüsü ile yeniden Tanrı'nın huzuruna çıkmaktan söz etmesi, trajik bilincinin anlık yansımalarından biridir sadece. Zira Demon'un bilincinin anlık yansımasını oluşturan yeniden doğuş işareti sonrasında: "Ve unutmak istediyse de/ Tanrı izin vermedi buna/ Zaten unutabilir miydi ki?" (Lermontov, 2019, s. 74) dizeleri Tamara ile buluşmanın Demon için yeni bir hayatın başlangıcı olmayacağına dair ufak bir ipucu içerir. Bu cümlelerde gururlu ruhun Tanrı'ya olan bağımlılığı kabul etmediği ve yeniden doğma arzusu alevlense bile önceki şeytani yaşam deneyimini unutmak istemediği duyumsanır. Bu duyumsayışa rağmen Demon'un Tamara ile karşılaşmasıyla aşkın kasvetli ruhunu ısıtacağı, aydınlatacağı, iyilik tapınağını bulacağına dair bir umut belirir. Kahraman tam bir yeniden doğuşa hazır gibidir bir adım ve başka bir dünyaya taşınacak, yalnızlıktan, hayal kırıklığından, can sıkıntısından, kötülükten, nefretten uzak yeni bir hayatı öğrenecektir (Yuryeva, 2012, s. 26).

Dilsiz çölünü ruhunun

Sevinçli bir ses doldurdu

Ve kavradı yeni baştan

Kutsalliğııı sevdanın

İyiliğin, güzelliğin!(Lermontov, 2019, s. 73).

Bu dizelerdeki vurgu, eserin ilerleyen kısımlarında güçlenir, Tamara'ya ulaşmak için manastıra giden Demon, bir an için tövbe kapısına yaklaşır, kayıtsızlıkta katı olan kalbi için ani bir seçim söz konusu olur, tövbenin ilk adımı atılır:

Ve olmayacak şey! Işı̆̆ı sönmüß̧ gözlerinden

Ağır bir gözyaşı damlamaktadır (Lermontov, 2019, s. 88).

Demon, ruhunun asırlık hasretini sonlandıracak adeta bir hediye olan dönüşüm mucizesini kabul etmeye hazır gibidir:

Ve giriyor hücresine Tamara'nın 
Sevmeye hazır, iyi olmaya;

İstenen zaman gelmiş gibidir

Başlamak için yeni bir yaşama (Lermontov, 2019, s. 89).

Ne var ki yeni bir yaşama adım atmaya hazırlanan Demon'u Tamara'yı koruyan melek karşılar ve şöyle seslenir ona:

Tedirgin ruh, günahkâr ruh

Yarı gece karanlı̆̆ında

Seni kim çă̆ırdı buraya?

Kendine hayran bulamazsin,

Kötülü̈k şimdiye kadar

Ayak basmadı buraya!

Benim sevgimde, tapină̆ımda

Suçluluğun izini bırakma!

Söyle kim çağırdı seni? (Lermontov, 2019, s. 89).

Koruyucu melekle karşılaşan Demon'un yeniden doğuş süreci bir anda kesintiye uğrar, tekrar kötü bir ruha dönüşür ve bakışları kıskançlıkla tutuşarak Tamara üzerinde bütünsel egemenliğini ilan eder:

Geç kaldın sen koruyucu.

İkimizin de üzerinde

Hükmün geçmez artık senin,

Gurur dolu o kalbin üstüne

Kendi damgami vurdum ben;

Burada senin kutsallı̆̆ın

Yer bulamaz artık kendine

Egemen de benim seven de(Lermontov, 2019, s. 90).

Tövbe, Demon'un doğasında yoktur. Nitekim Yuri Mann: "Şeytan, tövbe etmeden, yani şeytani özünde hiçbir şeyi değiştirmeden cennetle uzlaşmak ister" (Kumış̧, 2007, s. 131-135) der. Lermontov için de durum aynıdır. Genç şair içinde yaşadığı gerçekliğe boyun eğmeden, hiçbir uzlaşmaya girmeden yeni bir yaşam peşinde koşar. Nitekim Gümüş çağ dönemi Rus edebiyatının önde gelen şair ve edebiyat eleştirmenlerinden Dimitri Merejkovski, Lermontov için "Rus edebiyatında tamamen itaat etmeyen tek bir isim vardırO da Lermontov'dur" (Merejkovski, 2013, s. 405-406) sözleriyle şairin isyankâr ruhunun altını çizer. Demon ile Lermontov özdeşliğinde içinde yaşanılan gerçekliğin reddinin yanı sıra Tanrı'nın, Tanrısal düzenin reddi teması da gündeme gelir. Lermontov'u bu bağlamda eleştiren ilk isimlerden biri düşünür Vladimir Solovyov'dur. Düşünür, Demon imgesi bağlaminda Lermontov'u Friedrich Nietzsche ve üstün insan öğretisinin öncüsü olarak kabul eder. Solovyov, "Lermontov'un şiirine hâkim olan ve kısmen diğer biçimlerle karışık halde bulunan ana dürtülerin nihai manası Nietzsche'nin zihninde açıçca ayrı bir imgeye büründüklerinden beri bizim için tamamen şeffaf hale geldi" (Solovyov, 1991, s. 379) sözleriyle Lermontov'un yaratıcılığındaki Demon imgesinin Nietzcshe ve üstün insan öğretisi ile olan bağına vurgu yapar. Düşünüre göre her rasyonel eleştirinin görevi, eleştirinin öznesinin sahip olduğu ve çarpıttığı hakikati bulmaktır. Bu doğrultuda Lermontov'daki çarpıtma başka bir ifade ile yanılsama, kendisini üstün insan olarak görme eğilimidir. Bu eğilimin ilk görünümünü şairin düşüncelerinin bütünsel olarak kendisine

SEFAD, 2021; (46): 103-118 
yoğunlaşmış olması ele verir. Solovyov, bu konuda Puşkin ile bir karşılaştırma yaparak şöyle açıklar düşüncelerini:
Lermontov'un dehasının ilk ve ana özelliği, sıra dışı bir gerginlik ve düşüncenin, duygularm kişinin kendisi üzerinde korkunç bir güçle yoğunlaşmasıldr. Puşkin kendinden bahsettiğinde, sanki başka bir şeyden bahseder; Lermontov ise başka bir şeyden bahsettiğinde, düşüncesinin sonsuz mesafeden kendisine dönmeye çalıştı̆̆ hissedilir, derinlerde sadece kendisiyle meşguldür ve hep kendine döner (Solovyov, 1991, s. 384).

Solovyov, Lermontov'un Demon imgesi ile ilgilenmesini de doğasındaki şeytani öğelerle ilişkilendirir ve görüşlerini desteklemek için Lermontov'un çocukken çiçekleri koparması, sinekleri öldürmesi gibi kötülüğe olan meylinden söz eder. Şairin yaşam yolunu ve eserini analiz eden Solovyov, Lermontov'un yaşamı boyunca şeytani doğa ile hassas, zayıf bir şekilde hissedilen ilahilik arasında mücadele durumunda olduğu sonucuna varır. Lermontov'un şeytani olandan uzaklaşamamasına, onu içine çeken şeytani kibir neden olur. Düşünüre göre Demon'un ilahi olanın güzelliğini hissettiği ve Tamara'nın sevgisiyle bunun için çabaladığı eserde ortaya konan bu çatışmadır. Ne var ki kızı koruyan melekle tanışmanın ve yenilginin yaralı gururu, Demon'un sonunda kötülüğün yolunu tutmasını sağlar. Lermontov'un Demon'unu bu şekilde ele alan Solovyov, şaire özgü felsefeyi fatalist felsefe olarak adlandırır. Bir diğer araştırmacı Nikoleva da Demon'un fantastik imgesi, Lermontov için hayattan tatminsizliğin sembolü, yaşamın tüm olumsuz yönlerine, insanların zayıflığına, sersemliğine ve bayağılı̆̆ına karşı bir isyan ve böylesine kusurlu bir dünya yaratan Tanri'ya karşı bir protestodur der. (Nikoleva, 1956, s. 155). Değerlendirmelerini Lermontov'a şeytani doğa bağlamında yaklaşarak gerçekleştiren Solovyov'un düşünceleri, şairin yaşamını içinde yaşadığı gerçekliği değiştirme tutkusuna adaması, özgürlük ve hümanist ideallere olan bağlllı̆̆ı göz önünde tutulduğunda kabul edilemezdir. Ruhunda şeytani öğeler barındıran bir şair, idealleri uğruna sürgünlerle tamamlayabilir mi kısa ömrünü? Serflik sistemine dayanan toplumsal düzenin değişmesine güçlü bir arzu duyabilir mi? Evet, Lermontov ile Demon'u özdeştir ve bu özdeşlik en açık ifadesini eserin şu dizelerinde bulur:

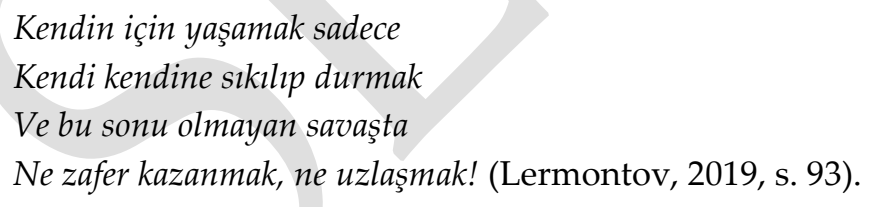

Ancak Lermontov, Demon'un aksine, Solovyov'un eleştirilerinin aksine, kendisi için yaşamaz, yaşayamaz. Ama tıpkı Demon gibi ne zafer kazanır ne de içinde yaşadığı gerçeklikle uzlaşır. Melekle giriştiği mücadeleyi kaybedip hayallerine lanet okuyan yenilmiş sürgün ruh gibi o da planlı bir düelloda, uzlaşamadığı yaşamdan zafer de kazanamadan erken yaşta ayrilır.

\section{Kaybedişin Sorgulanması}

Peki, neden yenilir bu iki isyankâr ruh, yazar neden kahramanı ile aynı yazgıyı paylaşır? Dini bakış açısından yaklaştığımızda bu sorunun cevabı Tanrı'dan kopan hiçbir bireyselliğin başarıya ulaşamayacağı yönündedir. Nitekim Rus din felsefesinin başlıca temsilcilerinden biri olan Solovyov'a göre Lermontov'un üstün insan yolu aslında Tanrı insanın saptırılmasıdır. Lermontov, insanlığın hakiki üstün insanlığa yani Tanrı insanlığa, girme yolunda önder olma misyonunu doğru anlayamaz, bu yüzden yok olur. Hristiyanlığı anlamaz çünkü itaat etmek istemez. Düşünüre göre Lermontov'u ebedi yıkımdan kurtarmak 
imkânsızdır. Solovyov'un Lermontov'a yönelik bu sert eleştirilerini değerlendiren Merejkovski, bu öfkenin nedenini Dostoyevski'nin Puşkin Konuşması'nda coşkuyla haykırdığı "Ey başını önüne eğ mağrur insan!" (Dostoyevski, 2009, s. 31) sözleriyle ilişkilendirerek açıklar. Eleştirmene göre itaat ve tevazu Ruslara doğanın ve tarihin öğrettiği temel özelliklerdir ve Rusya'nın toplumsal tarihsel yapısının bir parçası olan Rus edebiyatı da bu temelde itaatkâr bir edebiyattır. Puşkin isyan ettiğinde Çar I.Nikolay'a bir kaside yazarak itaat eder, Gogol isyan ettiğinde Ölü Canlar'ın ikinci cildini yakıp toprak köleliğini kutsayarak itaat eder, Dostoyevski isyan ettiğinde sürgüne gönderilir ve itaatin vaizi olarak geri döner. Lermontov ise sonuna kadar isyan eder ve onu yenilgiye, ölüme mahkûm eden de bu özelliği olur. Merejkovski'ye göre Demon'un "Gökle barışmak istiyorum" sözleri itaat etmek istemeyen Lermontov'un itirafıdır ve Tanrı mücadelesinde Tanrı oğlu olma çabasını gösterir. Ancak Lermontov, sınırı aşıp başarılı olamaz zira bunu başarmak için Hristiyanlığı kabul etmek, hatta aşmak gerekmektedir. Lermontov'un trajedisini de Hristiyanlığın üstesinden gelememesi oluşturur(Merejkovski, 2013, s. 422-423).

Dini bakış açısından Demon'un yenilgisinin açılaması ise sonsuza dek lanetlenme bağlamında yapılabilir. Nitekim araştırmacı Korovin, “Demon'un trajedisini oluşturan şey Tamara ile hayallerini hayata geçirememiş olması değildir, yeniden doğuşunun mümkün olmaması, kötü doğasını aşamamasındadır" (Korovin, 1973, s. 196) sözleriyle Demon'un kurtuluşunun imkânsızlığının altını çizer. Peki, sonsuza dek lanetle mühürlenen Demon yenilirken onun yoluna giren Tamara neden kurtuluşa ulaşır? Tamara'nın Demon ile olan ilişkisi adeta ilk günahın, bilgi ağacı meyvesinden ısırılmasını çağrıştırır. Nitekim Demon Tamara'ya şeytanın ilk insanlara vaat ettiği bilgi ve bilinç ile özdeş olan farklı bir yaşamı var eder:

Bırak zavallı dünyayı kendi yazgısına;

Gururlu bir bilinç derinliği

Kazandıracağım karşıllk olarak sana(Lermontov, 2019, s. 100).

Demon ile bilgi ağacı meyvesini ısıran Tamara ruhunun eski bütünselliğini yitirir. Tamara'nın ruhu birbiri ile ezeli zıtlık içinde olan iki kökenin savaş alanı haline gelir. Çıkış yolunu dünyevi yaşamdan uzaklaşıp manastıra gitmekte bulan Tamara için manastır, içsel çelişkilerden kaçma arzusunu sembolize eder. Ama beden ve ruh arasında eşit derecede dramatik bir ayrışmaya neden olur bu kaçış. Manastır ruh için kurtuluş getirir, ama beden için bir tabut olur (Korovin, 1973, s. 197). Tamara ruhunu saf-temiz tutmak ister, zira kötü bir ruh tarafından sınanmış aydınlık bir köken hâkimdir onda. Demon'da ise aksine yeniden doğmak için çabalayan kötü bir köken hâkimdir. Böylece eser boyunca karakterlerin baskın özelliklerinin değişmeden kaldığı gözlenir. Tamara ve Demon'un kaderini dramatik bir şekilde yeniden inşa eden çelişkilerin farklı doğası, karşılıklı çekim ve itişi belirler. Tamara, içsel mücadele ile diş dünyadan izole olurken Demon dünyaya karışır. Sonuçta Tamara kurtulur, melekler eşliğinde cennete gider, Demon ise kurtuluş umudunu yitirerek yeniden lanetler savurur. Demon'un yenilgisinin temel nedeni kötü doğasını aşamaması, yeniden doğuş yoluna Tamara'nın evleneceği adamı öldürerek yine bir kötülükle başlamasıdır. Oysa Tamara, Demon için gerçekten acı çeker. Zira bu acı ile Demon'un tüm çabasına rağmen mahrum kaldığı saf iyiliğe olan inancını, muhafaza eder.

Eserin sonunda şeytanın hayallerinin gerçekleşmemesi ancak Tamara'nın melekler eşliğinde cennete götürülmesinden, Hristiyan teolojisi bağlamında insana Tanrı' yla birleşme, yabancılaşmadan kurtulmanın bahşedilmiş olmasına rağmen şeytanın sonsuza dek 
lanetlendiği sonucunun yanı sıra kurtuluşun bütünsel iyilik ve tövbe ile mümkün olduğu, iyiliğin her daim kötülüğe karşı zafer kazanacağı sonucu da ortaya çıkar. Araştırmacı O. Yuryeva bu noktada önemli bir soru sorar: Peki okur neden kötüye karşı iyinin zaferinden kayıtsız şartsız sevinmesine engel olan bir kedere kapılır? Yuryeva'nın bu soruya verdiği yanıt, yazar kahraman özdeşliğinin bir kez daha altının çizilmesidir: Demon ve yazar arasında derin bir bağ vardır zira Demon'un sözlerinde, yazarın duygu ve düşünceleri, dünyaya, insan doğasına, dünyadaki ve insandaki iyiyle kötü arasındaki ilişkiye dair fikirleri okunur. Demon imgesinde somutlaşan evrensel kötülük, şair için dünyevi kötülükten, dünyevi yaşamı, insan yaşamını dolduran kayıtsızlıktan, kıskançlıktan, nefretten, anlamsızlıktan, hiçlikten daha evladır (Yuryeva, 2012, s. 32-33).

Kahramanların yenilgisine Lermontov'un dünya duyumsayışı, toplumsal politik görüşleri ve içinde yaşadığı çağın koşulları bağlamında bir cevap arandığında Demon'un mücadelesinin trajik sonucu ile yerine getirilmemiş, hayal kırıklığına uğramış umutlar çağıyla sıra dışı ilişki karşımıza çıkar. Dönemin aydınları öylesine bir hayal kırıklığına, yenilgiye mahkûm edilmişlerdir ki Lermontov'un çağdaşı olan Nikolay Stankeviç, "Zavallı, hasta, talihsiz çă̆!" diye haykırır ancak"Ne var ki öyle güzellikler öyle bir hümanizm var ki yaralarında inanmamak mümkün değil iyileşip yeniden doğacağına dünyanın" (Akt. Udodov, 1973, s. 397) sözleriyle tüm karamsarlığa rağmen bir yeniden doğuş 1şığına tutunur. Düşünürün sözünü ettiği "yeniden doğuş" motifi, buna dair umutlar, tüm çaresizliğe ve trajik duruma rağmen Lermontov'un Demon'unun içeriği ile kesişir. Dönemin bir diğer düşünürü Mihail Bakunin "Büyük fırtınalar, şimşekler sarsılmış dünya, senden korkmuyorum, seni küçümsüyorum, zira ben bir insanım! Ben bir insanım ve bir Tanrı olacağım" (Bakunin, 1987, s. 70) sözleriyle adeta Lermontov'un Demon'u ile birlikte Tanrısal düzene isyan eder.

\section{SONUÇ}

Dekabrist ayaklanması sonrası dönemi oluşturan 1830-40'lı yıllar Rusya'sında birey ve toplum sorunu çok daha keskin bir hal alır. Birey bu karanlık, umutsuz çağda hiç olmadığı kadar baskılanır, yasaklarla zulüm görür. Bu koşullarda birey sorunu insan onuru ve hakları iddiası merkezi sorun haline gelir. Özgürlüğe dayanan bireysellik, kaçınılmaz olarak içinde yaşanılan toplumsal yapı ile çatışmayı, bütünsel bir yadsımayı beraberinde getirir. Zira insanın onu çevreleyen gerçekliğin yenilenmesi ve uyumu için mücadele etmesi dışında kişisel yaşamın bütünlüğünü ve uyumunu elde etmesi imkânsızdır. Ancak Lermontov'un içinde yaşadığı koşullar onu yenilgiye mahkûm eder. İçinde yaşadığı toplumsal gerçeklik; Lermontov'un yeniden doğuş, yeni bir yaşam hayalinde kanatlarını kırar her daim. Yazar tıpkı kahramanı Demon gibi sürgün bir ruh, bir seyyah gibi dolaşır yeryüzünde ve ölüme yürüdüğü ikinci sürgüne giderken kaleme aldığı "Elveda Kirli Rusya" dizesiyle gözyaşı vadisine ilk vedasını gerçekleştirmiş olur.

\section{SUMMARY}

Man's first encounter with the Devil, also called the Demon, the disgraced angel of the divine religions, is predicated on the phenomenon of original sin. The devil persuaded Adam and Eve to eat the fruit of the tree of the knowledge by promising them knowledge and freedom, and so caused mankind to be expelled from heaven through this tempting. This became the beginning of man's history on earth. In this sense, the relationship between the Devil and man is quite old, and in the Middle Ages, when Christianity went through a 
solid development process; with respect to the original sin, it became aprevalent idea that humanity was under the rule of the Devil and was led by evil. In line with this idea, human beings had to walk on a path full of wrong doing sin the "valley of tears called the earth" under the control of the Devil.

In the poem the Demon written by the Russian writer Mikhail Yuryevich Lermontov, which is the subject of our study, the fate of the Devil in the valley of tears called earth, is reflected through the poet, the protagonist, and Tsar Nicholas I's Russia, which is the setting determined by Lermontov to signify the valley of tears. Lermontov works on the Demon for ten years of his life, and this work is considered as the author's most complex and contradictory work. The basic interpretation of the work indicates that the image of the Devil referred as the disgraced angel in the Bible, which was examined in a wide range of works such as Paradise Lost by John Milton, Faust by Johann Goethe and Eloa by Alfred de Vigny, is reconsidered in the spirit of Lermontov. Although this common perspective is in line with the content of the work, it wouldn't be a correct approach to discuss the Demon in such a narrow framework. When the poet's creativity and the struggle for survival are considered as a whole, it is of great importance to conduct the analysis of the work regarding the fate of the devil within the context of the author-protagonist relationship and the Russian reality of the period in question, rather than evaluating it as a biblical theme. In this sense, identifying the protagonist with the author was the starting point while evaluating the period in which Lermontov lived.

The way Lermontov senses the world is shaped within the framework of the socialeconomic conditions of Russia governed by Tsar Nicholas I, who took over the throne in 1825. Together with the Decembrist revolt, during his reign, Tsar Nicholas employs a very harsh administration policy. Executions, deportations, inhibiting any intellectual movements, heavy censorship laws are among the main features of Nicholas's Russia. Lermontov, starting from his youth, engages in a fierce protest and uprising against the socio-political order of Nicholas's Russia. However, the young poet is faced with exiles in response. In this context, Lermontov's search for unruly ways to fight the order in which he live sturns out to be painful disappointments. The poet refers to the Demon, the magnificent image of the glorious rebellion, for his indomitable protest, which ends up with no practical results. The Demon is the enemy of God and his imperfect creation as well as the life on earth, just like Lermontov.

In the work, the Demon's story begins with his reminiscences of life in heaven. As he fliesover the sinful world, he remembers the days when he was a pure soul and an archangel. Elements depicting the heavenly life of the Demon are faith and love, and he lives a peaceful life with no knowledge of evil or suspicion. The work continues with the gloomy depiction of the Demon's journey on earth. While the Demon defines earthly life as "Fading in silence around the narrow sphere / of cowardly and cold people" on the one hand, he wishes, on the other hand, to join this life with a strong desire. However, he is also aware of the objective impossibility of realizing this. The contradiction created by this awareness turns into a tragic and proud despair. Inner contradictions evoke the Demon's thoughts; he wishes to reconnect with both the earth and heaven. Feeling like a stranger to both worlds, the Demon falls in love with Tamara, who is about to get married, the moment he sees her, and tries to find the light of his rebirth in Tamara, a Caucasian beauty. When we look at the light of his salvation and rebirth in the reality of the context of Nicholas, to which 
Lermontov perceives himself as alienated, we encounter a strong desire for rejection and struggle, as in the Demon. Taken as a whole, the Demon, as a rebellious spirit who cannot belong to either world, reflects the Russian intellectuals of the period in general and Lermontov himself in particular. In this identification, however, the Demon's rebellion is much closer to that of Lermontov, given Lermontov's criticism of his contemporaries. As a matter of fact, Lermontov describes his contemporaries as desperate prisoners in the face of power in his famous poem Duma written in 1838 which starts with the line "In sorrow I gaze upon my generation!"

In the identification of the Demon with Lermontov, as well as the rejection of the reality lived in, the rejection of the God and the divine order comes to the fore. One of the first names to criticize Lermontov in this context was the philosopher Vladimir Solovyov. The philosopher regards Lermontov as the forerunner of F. Nietzsche and the Nietzscheism in the context of the Demon image. The ideas of Solovyov, who made his evaluations by approaching Lermontov in the context of demonic nature, are unacceptable considering the poet's dedication to his passion to change the reality in which he lives and his commitment to freedom and humanist ideals. Can a poet with demonic elements in his soul complete his short life with exiles for the sake of his ideals? Can he have a strong desire to change the social order based on serfdom?Yes, Lermontov and the Demon are identical. Lermontov, just like the Demon, neither gains a victory nor comes to terms with the reality in which he lives. Just like the defeated, exiled soul who has lost his fight with the angel and cursed his dreams, he leaves life, with which he could not reconcile, at an early age in with a planned duel, without a victory. So why are these two rebellious souls defeated, why does the author share the same fate as his protagonist? From a religious point of view, the answer to this question is that no individuality that breaks with God can succeed. From a religious aspect again, the Demon's defeat can be explained in the context of eternal damnation. "The Demon's tragedy is not that he failed to realize his dreams with Tamara, but that his rebirth was not possible, that he could not overcome his evil nature". When an answer is sought for the protagonist's defeat within the context of the ways Lermontov senses the world, his socio-political views, and the conditions of the period in which he lives, an extraordinary connection appears with the period of expectations that is unfulfilled as a tragic result of the Demon's struggle and filled with disappointments. The problem of the individual and the society becomes much more acute in Russia in the 1830s and 40s, which constitutes the postDecembrist revolt period. In this dark, desperate age, the individual is oppressed and persecuted by prohibitions more than ever. In these circumstances, the problem of the individual and claims of human dignity and rights become the central concern. The individualism which is based on freedom inevitably brings about conflict with the existent social structure and a who listic denial together with it. However, Lermontov is destined to be defeated by the circumstances in which he lives. The social reality Lermontov faces always damages his wings carrying his dreams of rebirth and a new life. Lermontov, like his protagonist the Demon, wanders the earth like an exiled soul, a traveller, and makes his first farewell to the valley of tears with his line "Farewell Unwashed Russia " that he wrote on his way to his second exile on which he embraces death. 
Makale Bilgileri

Etik Kurul Kararı:

Katılımeı Rizası:

Mali Destek:

Çıkar Çatışması:

Telif Hakları:
Etik Kurul Kararından muaftır.

Katılımci yoktur.

Çalışma için herhangi bir kurum ve projeden mali destek alınmamıştır.

Çalışmada kişiler ve kurumlar arası çıkar çatışması bulunmamaktadır.

Telif hakkına sebep olacak bir materyal kullanılmamıştır.

Article Information

EthicsCommitteeApproval: InformedConsent:

Financial Support:

Conflict of Interest:

Copyrights:
Exempt from the Ethics Committee Decison.

No participant.

No financial support from any institution or Project.

No conflict of interest.

No material subject to copyright is included. 


\section{KAYNAKÇA}

Andreyevski, S. A. (1913). Literaturnıye oçerki. Peterburg: Novoye vremya.

Bakunin, M. (1987). İzbrannıye filosofskiye soçineniya i pisma. Moskva: Miysl.

Balıkçığlu, Z. (1994). Kötülük tekilcilik postmodernizm. İstanbul: Mitos Yayınları.

Çaadayev, P. (2009). Filosfskiye pisma. Moskva: Terra.

Dostoyevski, F. (2009). Puşkin konuşması (T. Ağaoğlu, Çev.). İstanbul: İletişim Yayınları.

Foht, U. (2013). Demon Lermontova kak yavleniye stilya. M.YU. Lermontov Pro et Contra, Peterburg: Russkoy Hristiyanskoy gumanitarnoy akademi.

Gogol, N. (1952). Polnoye sobraniye soçinenii v 14 tomah Tom 8 Stati. Moskva: AN SSR.

Hampson, N. (1991). Aydınlanma çă̆ı (J. Parla, Çev.). İstanbul: Hürriyet V. Yayınları.

Hertsen, A. (1989). M. YU. Lermontov $v$ vospominaniyah sovremennikov. Moskva: Hudojestvennaya literatura.

Jestkova, A. (2014). Religiozniye motiviy v poeme M. YU. Lermontova Demon, Jurnal Aktualnıye voprosiy sovremennoy filologii i jurnalistiki. Viypusk 13, 66-71.

Korovin, V. İ. (1973). Tvorçeski put M.YU. Lermontova. Moskva: İzdatelstvo Prosveşeniye.

Kumiyş, V. (2007). Nekotoriye osobennosti postroeniya obraza Demona y poeme M. YU. Lermontova Demon. Vestvik Kostromskogo gosd. Universiteta.3, 131-135.

Lermontov, M. (2014). Benim İbilisim. Lermontov Profil (K. Yükseler. Çev.). İstanbul: YKY Yayınları.

Lermontov, M. (2019). Hançer seçme şiir ve manzumeler (A. Behramoğlu, Çev.). İstanbul: İş Bankası Kültür Yayınları.

Loginovskaya, E. (1977). Poema M.YU. Lermontova Demon. Moskva: Hudojestvennaya literatura.

Merejkovski, D. (2013). M.YU. Lermontov poet sverh çeloveçestva. M.YU. Lermontov Pro et Contra. Peterburg: Russkoy Hristiyanskoy gumanitarnoy akademi, 400-439.

Nikoleva, M. F. (1956). Mihail Yuryeviç Lermontov Jizn i tvorçestvo. Moskva: Gosudarstv. İzdatelstvo.

Russell, J. B. (2018). Lucifer Ortaçă̆'da Şeytan. (A. Fethi Çev.). Ankara: Panama Yayıncilık.

Sakulin, P. N. (1914). Zemliya i nebo v poezii Lermontova. Venok M.YU. Lermontovu: Yubileyniy sbornik, Moskva: Dumnov.

Solovyov, V. (1991). Filosofiya iskusstva i literaturnaya kritika. Moskva: İskusstvo.

Udodov, B. T. (1973). M.YU. Lermontov hudojestvennaya individualnost $i$ tvorçeskiye protsessiy. Voronej: Voronejskogo Universiteta

Viskovatıy, P. A. (2004). Jizn i tvorçestva M.YU. Lermontova. Moskva:Gelios ARV.

Yuryeva, O.YU. (2012). Tvorçeski put M.YU. Lermontova 1814-1841. İrkutsk: FGBOU. 